\title{
Comparative therapeutic effectiveness of probiotic and combinations of Probiotic with prebiotics and probiotic with rumenotorics in experimentally induced ruminal acidosis sheep
}

Melkie Dagnaw Fenta ( $\square$ melkiedagnaw3528@gmail.com )

University Of Gondar

Wudu temesgen Jemberu

University Of Gondar

Ashenafi Assefa G/mariam

University Of Gondar

Atsede solomon Mebratu

University Of Gondar

Research Article

Keywords: prebiotics, probiotics, rumenotorics, ruminal acidosis, sheep

Posted Date: January 4th, 2021

DOI: https://doi.org/10.21203/rs.3.rs-129885/v1

License: (9) This work is licensed under a Creative Commons Attribution 4.0 International License. Read Full License 


\section{Abstract}

\section{Background}

rumen disorder is responsible for huge economic losses in ruminants due to decrease in production and increase in expenditure towards treatment. Acidosis is one of the most ruminal disorders, characterized by changes in the rumen environment and leds to systemic acidosis. To correct this disorder, recent alternative trends in sheep rearing have led to the use of prebiotics, rumenotorics and probiotics as feed additives or treatment.

Context and purpose

this study was to evaluate and compares the therapeutic effectiveness of probiotics, a combination of probiotics with prebiotics, probiotics with rumenotorics and with the standard treatment under experimentally induced acidosis.

\section{Methods}

the experimental study design was conducted from September to May 2019. For therapeutic study 25 sheep were randomly divided into 5 groups with deliberately imposed ruminal acidosis as a group comprising of 5 animals each.

Results

acidosis was induced by an oral dose of $50 \mathrm{~g} / \mathrm{kg}$ with wheat flour after 24-hour fasting. Four therapeutic regimes and negative control group were employed, I-Probiotics, II-Probiotics with Prebiotics, III-Probiotics with Rumenotorics and IV-Standard treatment (sodium bicarbonate) was adopted. Then, laboratory analysis of rumen fluid, physical parameters and hematological changes before and after treatment was carried out. From a comparison of each treatment groups with the control group to correct ruminal $\mathrm{pH}$, the combination of probiotics with rumenotorics, the mean \pm SD before treatment (4.96 \pm .837$)$ increased to (5.92 \pm .54$)$, (6.30 $\pm .41),(6.75 \pm 0.34)$ after treatment, was statistically significant $(p<0.05,0.024,0.047,0.002)$, from day one-day three, respectively, and the therapeutic regimens of probiotics with rumenotorics was highly significance compare with control group ( $p$ $<0.05, p=0.001 \& p=0.000$ ) improved heart rate and respiratory rate at day three after treatment and the mean PCV value of treatment Group III was $38.00 \pm 6.819$ before treatment changed to $34.60 \pm 5.367,29.80 \pm 6.261$ and $24.80 \pm 10.134$ after treatment, were statistically significance $(p<0.05, p=0.003, p=0.02 \& 0.006)$ from day one-day three, respectively.

Conclusion

the present study was concluded that probiotics with rumenotorics administered together were the most successful therapeutic regimen for improvement of ruminal acidosis. Therefore, in this experimental study for the treatment of acidosis, it has been recommended that use of probiotics with substrate is the promising alternative.

\section{Introduction}

Ruminant animals can possibly influence the financial and social part of most of African rural communities. Fifty-three percent of the total ruminant animals, small-ruminant like sheep and goat population in the developing countries are found in Asia, particularly in India and Pakistan [1]. Ethiopia has around twenty eight million sheep in different Local sheep breeds [2] and they may be grouped into about 14 traditional sheep populations mainly based on their location [3].

Sheep considerably contribute to the agrarian economy and take part a vital role in the lively hood security of marginal and landless ranchers [4]. They provide household nutritional security and family income through meat, wool, skin, milk, and manure with small or no feed supplementation [5]. Nevertheless, the accomplishment of the sheep industry in Ethiopia has been poor compared with other African countries [6] due to insufficient feed and nutrition, prevalent disease and other health-related trouble, poor management, and marketing system. Among the different health problems of ruminants, ruminal disorders cause significant economic loss to the producers in the form of wasted feed, delayed marketing and condemnation of rumen and liver or entire carcass, brought down nutritional value, reduced water binding capacity of meat and several organoleptic deficiencies and death of animals[7] 
Ruminal acidosis is mismanagement disease (incorrect feeding system) and sometime man made disorder of ruminants, particularly fattening animals [8]. The most common causes of acidosis include engorgement of apples, corn, wheat, sugar beets and concentrated sucrose solutions. In clinically sick ruminants, morbidity rate varies from $10-50 \%$ and death in lactic acidosis may reach up to $90 \%$ not treated cases whereas it may be $30-40 \%$ in properly managed or treated case [9].The clinical and pathophysiological consequences of acidosis are hemoconcentration, dehydration, diarrhea cardiovascular collapse, kidney failure, muscle fatigue, sudden upsetting associated with a fall in blood pressure, and death. Animals that survive induce mycotic ruminatis in for long period of time, hepatic necrobacillosis due to migration of the microorganism from rumen to liver or chronic laminitis due to septicemia as well as evidence of ruminal scars [10].

This challenge is predominantly the relation to the abrupt change of the ration because the type of diet influences the number and species of bacteria and protozoa in the rumen and a change requires a period of microbial alteration. At the same time as the ruminal $\mathrm{pH}$ declines, the amplitude and frequency of the rumen contractions are diminished and at approximately a pH of 5 , there is ruminal atony [11]. Systemic changes happening at some stage in lactic acidosis necessitate a greater understanding of appropriate treatment and preventive measures to reduce the risk of grain engorgement in ruminants. Hematological and biochemical changes in ruminal acidosis are important to assess the seriousness of the disease and severe dehydration and cardiovascular involvement are common [12].

An understanding of the effective and efficient therapeutic regimen for the ruminal disorder is very essential for the successful management of ruminal acidosis. Recent trends in sheep rearing have led to the use of prebiotics, rumenotorics and probiotics as feed additives or treatment to promote growth by increasing feed efficiency, improving rumen motility and manipulating rumen microbial flora [13]. Probiotics are live microorganisms that beneficially affect the host upon ingestion by improving the balance of the gastrointestinal microflora [14]. Lactic acid producing bacteria (Lactobacilli and Enterococci) provide a constant lactic acid supply in the rumen, stimulate lactate utilizing bacteria [15] and stabilize the ruminal pH [16]. Probiotics can contain prebiotics as substrates and then they are called symbiotics, responsible for improving animal performance [17] and probiotics are one of the best antibiotic alternatives [18].

Prebiotics as non-digestible food components, which evade digestion by mammalian enzymes, reach the colon in an intact state and are metabolized by the beneficial members of the indigenous microbiota [19]. Prebiotics (Fructo Oligo Saccharide) encourage the growth of the beneficial bacteria in the gastrointestinal tract of the ruminants [20]. Rumenotorics (Antimony Pottasium Tartarate, Ferrous sulfate, copper and cobalt) act as co-factors required for vitamin B12 synthesis and acts as the substrate for growth of rumen microbes, restoration of deranged rumen function and subsequent revival of appetite [21]. Rumenotoric drugs (bolus Rumenotars) used to restore rumen motility and appetite as well [22).

\subsection{Statements of the problem}

Ruminants are important livestock species in developing countries. In global sense, the population of small ruminants from the world's shoat, $65 \%$ sheep and $95 \%$ goats, are located in developing countries, but low productivity and insufficient income generation. In Ethiopia so many sheep populations are reared in varied agro-ecologies and production systems for multiple purposes such as meat production, income generation, and as a source of the skin; contributing significantly too small scale farmers' livelihoods [6]. However, the contribution from sheep production in Ethiopian economy is adversely affected by several constraints such as inadequate feed and nutrition, widespread disease, poor management and other health-related problem. Among different health problems, rumen disorders had a great economic loss because of the high morbidity and the great losses in both the production and costs of treatment. From the economic point of view, fore-stomach diseases result in great losses to the producers through deaths, wasted feed, delayed marketing unthriftness of the recovered animals, incomplete utilizing of disease provoking food and extra labor costs of preventive and therapeutic measures[23].

The most common rumen disorder is usually ruminal acidosis that arises from ingestion of a large quantity of carbohydrate-rich diet, causing proliferation of lactic acid producing rumen bacteria particularly Streptococcus which results in heavy mortality [13]. During acute ruminal acidosis, the higher proton concentration especially amount of lactate in the rumen influences the integrity of the ruminal epithelial cells with small lesions and parakeratosis that can insult directly ruminant's metabolism system [24]. Furthermore, the acidic environment, the high osmotic pressure, and the high concentration of lactate in the rumen can cause 
death and lysis of the gram-negative bacteria. It causes relevant metabolic disorders such as laminitis, displacement of the abomasum [25], fatty liver, and sudden death syndrome [26]. So that correction of ruminal acidosis with potential alkalizing agents (magnesium oxide and sodium bicarbonate) is common in our country and their therapeutic effect is only neutralized the acid which is formed from acid forming feeds. Currently, the use of probiotics and prebiotics additives is developing as alternatives to improve ruminal disorder [10]. Recent evidence indicates that yeast and bacterial probiotic (BP) products can be an effective (not only neutralized acid) and economical alternative to using traditional buffers for moderating ruminal $\mathrm{pH}$ [27]. The impact of probiotics and the physicochemical conditions of the rumen digesta on the survival of pathogenic strains could have significant implications for farm management practices and food safety as well as decrease the risk of food-borne illness [28] .The growth of pathogenic bacteria also can be hindered by the synthesis of antimicrobial peptides by probiotics, such as bacteriocins or the production of enzymes able to hydrolyze bacterial toxins [29]. However, the use of probiotics and its positive effect on the ruminal micro biota has not yet received enough attention in our country.

The main objective of probiotics and prebiotics is to stimulate the growth of lactate utilizers' bacteria in the rumen. Therefore, they have a central role to decrease the risk of ruminal acidosis. Lactate-consumers bacteria also proposed as probiotics and used successfully to decrease concentrations of lactate, promote the damaged microbiota due to acidosis and maintain a ruminal pH [30]. In Northwest Ethiopia there no any study to show experimental trial to evaluate and compare therapeutic effects of probiotics, rumenotorics, and combination of probiotics with prebiotics and probiotics with rumenotorics in the treatment of ruminal acidosis in sheep. Keeping this in view, the present study was planned with the following objectives:

\subsection{Objective}

\subsubsection{General Objective}

- To compare the therapeutic effectiveness of different alternative ruminal acidosis treatments including probiotics, a combination of probiotics with prebiotics, probiotics with rumenotorics and the standard treatment of experimentally induced acidosis in sheep, central Gondar Northwest Ethiopia.

\subsubsection{Specific Objectives}

- Evaluate therapeutic effectiveness of alternative treatments in experimentally induced acidosis in sheep.

- Compare the therapeutic effectiveness of alternative treatments in experimentally induced acidosis in sheep.

- Compare the therapeutic effectiveness of the alternative ruminal acidosis treatments with the standard treatment to treat experimentally induced acidosis in sheep.

\section{Materials And Methods}

\subsection{Study Animals}

\subsubsection{Exclusion and Inclusion Criteria}

Local breed sheep were bought from the same origin and as much as possible equivalent age, body condition and similar physical size are as inclusion criteria for experimentally induced acidosis intervention whereas those animals pr-exposed (adaptive) for grain overload are as exclusion criteria.

\subsubsection{Housing and Husbandry}

The housing was well structured because for each group they have their own room. it was well ventilated and enough space(3 mx4m) for each group. Animals allowed move freely and manure was removed daily mechanically a solid dung.

\subsubsection{Animal care and monitoring}

Animals were monitor daily on their shelter and deworming twice in the study period. We provide adequate water and feed daily. As veterinarian always we had checked up the discomfort and diseased condition of the animals. 


\subsection{Study Area}

The study was performed in University of Gondar at college of veterinary medicine and animal science, on the farm in the laboratory animal's room.

\subsection{Experimental Design and Period}

All experimental animals were bought from the market, so animal-owner consents not applicable. After obtaining ethical approval from the "Ethical Review Board of the University of Gondar" as the support of college of veterinary medicine, Ethical committee. A statement to confirm that all protocols were carried out accordance with relevant guidelines and regulations We have also used as reference animal Research Reporting of in Vivo Experiment (ARRIVE guidelines 2.0) and take as baseline publish articles listed on the reference portion of the manuscript (Reference number 31 and 46). experiment was conducted from September 14 to May 2019 to evaluate and compare the therapeutic effectiveness of probiotics, combination of probiotics with prebiotics and probiotics with rumenotorics in treatment of acidosis in sheep. Completely randomized experimental design was assigned for different treatments to the study animals after induction of acidosis. There were 5 experimental groups namely negative control group, probiotics, probiotics plus prebiotics, probiotics plus rumenotorics and sodium bicarbonate (standard treatment). In each group 5 sheep of equivalent age, body condition and physically similar size were randomly assigned. The total number of animals used for the study was 25 sheep. The experimental procedure was divided into five phases;

Phase 1: Pre-induction phase, evaluation general health status of the animals Phase 2: Fasting phase for 24 hours Confined all sheep in the their room until 24 hours

\subsection{Feeding and Management System of Animals}

Animals were housed in separate cages with wooden floors and free access to water, an environmentally controlled room. During the experimental periods, animals were fed $50 \mathrm{~g} / \mathrm{kg}$ of wheat flour orally dosed according to the experimental design after $24 \mathrm{hrs}$ fasting period to induce acute ruminal acidosis [31].

\subsection{Therapeutic Intervention}

For therapeutic study 25 were randomly divided into 5 groups with deliberately imposed ruminal acidosis as a group comprising of 5 sheep each. Subsequently, ruminal acidosis was induced by an oral dose of $50 \mathrm{~g} / \mathrm{kg}$ with wheat flour after 24-hours fasting. Then four different types of treatments were allocated randomly to ascertain the comparative efficacy of various regimens by comparing with the negative control group and within the group. Randomized control design was adopted for assessing the ameliorative potential of probiotics and the combinations of probiotics with rumenotorics, probiotics with prebiotics and sodium bicarbonate those animals suffering from the ruminal disorder. Four therapeutic regimens were employed TI - probiotics, TIIprobiotics with prebiotics, TII-probiotics with rumenotorics, TIV-standard treatment/sodium bicarbonate and TV-negative control group was adopted for the study as per protocol is given as showed (Table 1). Sampling was performed before the onset of treatment and thereafter on 1st, 2nd, and 3rd -day of post-treatment [32]. 
Table 1

Therapeutic trial design in sheep with deliberately induced ruminal acidosis

\begin{tabular}{|lllll|}
\hline Group & $\begin{array}{l}\text { No. of } \\
\text { Animals }\end{array}$ & Treatment & Route dose & Duration \\
\hline Treatment(I) & 5 & Probiotic & Oral $1 \mathrm{~b}$, b.i.d & 3 days \\
\hline Treatment(II) & 5 & Probiotic\&Prebiotic & Oral $1 \mathrm{~g} \mathrm{b.i.d}$ & 3 days \\
\hline Treatment(III) & 5 & Probiotic\&Rumenotoric & Oral $1 \mathrm{~g} \mathrm{b.i.d}$ & 3 days \\
\hline Treatment(IV) & 5 & Sodium bicarbonate & Oral1.1 mg $/ \mathrm{kg}$ & 3 days \\
Treatment(V) & 5 & Negative control & untreated & - \\
\hline *b.i.d = twice a day, $\mathrm{b}$ = bolus & & \\
\hline
\end{tabular}

\subsection{Experimental Data Collection}

\subsubsection{General physical examination}

General physical examination including; clinical signs, body temperature, heart rate, and respiratory rate were taken from animals before and after treatment. Heart rate expressed in a number of beats per minute and was measured using a stethoscope and a stopwatch for 30 seconds and multiplying the result by two to obtain this record in minutes. The respiration rate was measured by a stethoscope expressed in a number of breaths per minute was measured using a stethoscope and stopwatch upon auscultation of respiratory movements for 30 seconds and the value obtained multiplied by two to obtain this result in minutes [33]. Body temperature was measured with a clinical thermometer. The thermometer was shacked to bring the mercury down in the column of the thermometer below the lowest point was recorded. It was kept in the rectum for two minutes with care in close contact with the wall of the rectum. Then it was taken out of the rectum and reading of the body temperature was recorded [34].

\subsubsection{Evaluation of hematological parameters}

Blood sample was collected from the jugular vein into $5 \mathrm{ml}$ out of which $2 \mathrm{ml}$ of blood was taken in EDTA $(1.5 \mathrm{mg} / \mathrm{mL}) \mathrm{containing}$ vials for the estimation of hemoglobin $(\mathrm{Hgb})$, blood $\mathrm{pH}$ and packed cell volume (PCV) and was kept at $4^{\circ} \mathrm{C}$ as per method described by [35] and rest $3 \mathrm{ml}$ of blood was kept at $-80^{\circ} \mathrm{C}$ until the serum analysis performed by using automatic hemo analyzer.

Determination of blood pH was performed by collecting $5 \mathrm{ml}$ whole blood into a test tube from the jugular vein using 19 gauge needles and allowed to clot at room temperature for $1 \mathrm{hr}$ to obtain serum. Serum $\mathrm{pH}$ was measured with the use of a wide range $\mathrm{pH}$ indicator paper and $\mathrm{pH}$ meter. The $\mathrm{pH}$ indicator paper was dipped into serum and the color of the strip was matched with the standard colors. The reading of the strip was taken immediately after dipping to avoid the change in color by exposure to air. The reading of the $\mathrm{pH}$ meter was recorded and the mean value of both the readings was calculated [36].

\subsubsection{Physical and Micro-Biochemical Examination of Rumen Fluid}

Physical parameters of ruminal liquor (color, consistency, odor and SAT) were evaluated. Also, Micro-biochemical changes including protozoal motility, density, MBRT, $\mathrm{pH}$ of rumen fluid, and Gram's staining of rumen fluid were examined in ruminal acidotic sheep and compared with diseased and positive control sheep after treatment.

The power of hydrogen $(\mathrm{pH})$ in ruminal fluid was measured with a portable $\mathrm{pH}$ meter before and after the treatment. Approximately, $5 \mathrm{~mL}$ ruminal fluid was collected aseptically through rumenocentesis at left paralumbar fossa using 16 gauge needles with a disposable syringe for the estimation of $\mathrm{pH}$ and protozoal activity [37]. The $\mathrm{pH}$ was measured using a wide range $\mathrm{pH}$ indicator paper and $\mathrm{pH}$ meter. The ruminal fluid was put on the paper and $\mathrm{pH}$ was recorded by a change in the color of indicator paper and matching it with the standard colors of the indicator paper. The $\mathrm{pH}$ of ruminal fluid was determined immediately after collection before exposure to air as it can cause an increase in $\mathrm{pH}$ if exposed to air. Besides, the ruminal fluid was put in beaker and $\mathrm{pH}$ meter was inserted and the $\mathrm{pH}$ value was recorded as the mean value [38]. The $\mathrm{pH}$ sensor was

Page 6/18 
calibrated with $\mathrm{pH} 6.67$ buffer solutions at the start of each experiment and was placed in the sampling bottle. Ruminal pH was recorded continuously every $10 \mathrm{~min}$ throughout the experimental period. After measured each sample, the pH sensor was washed by tap water throughout the trial.

Rumen fluid smear was prepared and stained with Gram's stain to observe either gram positive or gram negative microflora was dominated. Gram stain was evaluated bacterial diversity and revealed a shift from gram-negative organisms to a population of predominantly gram-positive organisms during ruminal acidosis. Few drops of ruminal fluid were placed on a glass slide with a toothpick and cover slip is put on it to see the motility of ruminal protozoa. The slide was examined under low power of microscope for the presence or absence of ruminal protozoa immediately after the draw the fluid from a test tube. Herein, protozoan motility was graded in four categories: ++++ highly motile and very crowded (good) : >10 mobile protozoa per field; +++ motile and crowded (fair): 6-9 mobile protozoa per field; ++ sluggish motility and low number (subnormal): 3-5 mobile protozoa per field; + no or sporadic alive fauna (very low) : $<3$ mobile protozoa per field [37].

Cellulose digestion test was also assessed by taking $10 \mathrm{ml}$ of filtered rumen fluid and mixed $0.3 \mathrm{ml}$ of $16 \%$ glucose in a test tube and immersed a thread of pure cellulose. One end of the tube which was tied lower weighted by a glass bead and incubated the tube at $37{ }^{\circ} \mathrm{C}$. Finally; the time was recorded for the bead to be dropped free at the bottom of the tube. As the same time methylene blue reduction test (MBRT) was performed to check the anaerobic fermentative metabolism of the bacterial population. To perform this activity, $6 \mathrm{ml}$ ruminal fluid was taken and mixed with $0.03 \%$ Methylene blue in the test tube. Then, it was incubated in $37^{\circ} \mathrm{C}$ for six minutes. Finally, the time was measured needed for the color of the mixture to be changed before and after treatment. Sedimentation activity test (SAT) was done at the induction phase of the acidosis and after therapeutic procedures to check the sedimentation features of the particles. Sample of rumen fluid was put in a test tube and stand properly. The time was measured needed for completion of sedimentation of fine particles and floatation of coarse solid particles. Moreover, glucose fermentative test was conducted when $0.5 \mathrm{ml}$ of $16 \%$ glucose was added with $10 \mathrm{ml}$ ruminal fluid in the test tube and kept the fluid on the saccharometer at $39^{\circ} \mathrm{C}$ and the result was recorded after 30 minutes.

\subsubsection{Data Management and Statistical Analysis}

Collected data were coded and entered to MS Excel spreadsheet and checked for accuracy. After validation, it was transferred and processed using computer software STATA version 14 for analysis. The data were statistically analyzed using analysis of variance (ANOVA) technique and paired t-test. The hematological, biochemical and physical parametric changes between different experimental groups was analyzed using one-way ANOVA with a Bonferroni multiple comparison test. The difference in hematological, biochemical and physical parameters before and after treatment for each treatment group was analyzed by paired t-test. For statistical inference, P-value $<0.05$ (at $5 \%$ level of significance) was be considered as statistically significant.

\section{Results}

\subsection{Induction of Acidosis and Recovery Rate}

In all study sheep, acidosis was successfully induced and all acidosis induced sheep showed nervous depression and symptoms including watery, yellowish, and acidic smelling diarrhea, cessation of feed intake, and severe symptoms of foot pain and difficulty walking after the induction of acidosis. All the sheep were able to stand move but they move slowly with head hung down and dull eyes. The results of the present study revealed that most of the therapeutic regimens tested in the experiment were found to be effective in eliciting a favorable response in acidosis sheep. Except one sheep (20\%) died from the treatment I (probiotic alone) there was no death due to induced acidosis in the treatment groups as compared to the death of two sheep $(40 \%)$ in the control group.

\subsection{Improvements of Physical Parameters}

At the start of the experimental period (before treatment), the total mean heart rate of $139.84 \pm 9.290$ in all groups of animals changed in to $127 \pm 0.20,109 \pm 9.540$ and $98.27 \pm 8.49$ in the $1^{\text {st }}, 2^{\text {nd }}$ and $3^{\text {rd }}$ days, respectively after treatment so that difference being significant $(p<0.05)$. Three treatment groups such as treatment group II, III and IV were statically significance difference 
comparing with control group at day three after treatment. The treatment group III, combination of probiotics and rumenotorics was most therapeutically effective for correction of heart rate on day three which was statically significance $(p<0.05, p=0.001)$. The standard treatment had also high significant difference between control groups in the improvement of heart rate $(p<0.05$, $p=0.008)$ next to probiotics and rumenotorics and the combination of probiotics and prebiotics (II) statically significance $(p<0.05$, $p=0.01$ ). Similarly rectal temperature was $37.9 \pm 0.612^{\circ} \mathrm{C}$ in all groups, while the temperature was $38.36 \pm 0.97,39.00 \pm 0.617$ and $40 \pm 0.0$ with the $1^{\text {st }}, 2^{\text {nd }}$ and $3^{\text {rd }}$ days, respectively, after treatment showing improvement in body temperature of the sheep (Table4).

The standard treatment (IV) was improved rectal temperature from day one-day three compare with control groups and these improvements were statistically significant difference $(P<0.05)$ (Table4). The mean \pm SD respiration rate (breath/minute) was $36.96 \pm 8.085$ before administered treatments in all groups of the animals at the induction phase but after treatment it was changed to $28 \pm 5.745,26.00 \pm 0.18,19.27 \pm 3.47$ for three consecutive days, it was statically significant $(p<0.05)($ Table4). Therefore, the therapeutic regimens of probiotics with rumenotorics was highly statically significance $(p<0.05, p=0.001 \& p=0.000)$ to improve the heart rate and respiratory rate compared with untreated group.

Table4: Effect of various treatment regimens on physical parameters for induced acidosis

\begin{tabular}{|c|c|c|c|c|c|c|c|}
\hline Parameter & $\begin{array}{l}\text { Time of } \\
\text { Rx }\end{array}$ & $\begin{array}{l}\text { Control } \\
\text { group }\end{array}$ & Treatment I & Treatment II & Treatment III & Treatment IV & Total mean \\
\hline Heart rate & Before & $134.40 \pm 9.21$ & $142.40 \pm 10.88$ & $140.80 \pm 14.45$ & $142.80 \pm 8.67$ & $138.8 \pm 7.16$ & $139.84 \pm 9.29$ \\
\hline \multirow[t]{4}{*}{$(\min )$} & $\begin{array}{l}\text { After } \\
\left(R_{X}\right)\end{array}$ & & & & & & \\
\hline & Day1 & $138.00 \pm 8.72$ & $127.20 \pm 7.16$ & $123.20 \pm 8.67$ & $123.20 \pm 126^{\#}$ & $116.40 \pm 4.6$ & $127 \pm 0.20$ \\
\hline & Day2 & $124.00 \pm 6.93$ & $116.00 \pm 8.64$ & $104.80 \pm 5.23^{\#}$ & $108.8 \pm 7.64^{\#}$ & $102.40 \pm 4.6^{\#}$ & $109 \pm 9.540$ \\
\hline & Day3 & $112.67 \pm 3.05$ & $107.00 \pm 8.87^{\#}$ & $97.20 \pm 6.88^{\#}$ & $91.20 \pm 7.69 \#$ & $98.00 \pm 8.00^{\#}$ & $98.27 \pm 8.49$ \\
\hline Temperature & Before & $38.40 \pm 8.764$ & $38.00 \pm .707$ & $37.60 \pm 548$ & $37.40 \pm .548$ & $38.20 \pm .447$ & $37.9 \pm 0.612$ \\
\hline \multirow[t]{4}{*}{ (T0) } & $\begin{array}{l}\text { After } \\
\left(R_{X}\right)\end{array}$ & & & & & & \\
\hline & Day1 & $38.60 \pm .89$ & $38.20 \pm .837$ & $38.00 \pm .707$ & $38.80 \pm .447^{\#}$ & $39.20 \pm 1.05^{\#}$ & $38.36 \pm 0.97$ \\
\hline & Day2 & $38.60 \pm .000$ & $39.00 \pm .000$ & $38.40 \pm 548$ & $39.40 \pm .548$ & $39.20 \pm .837^{\#}$ & $39.00 \pm 0.67$ \\
\hline & Day3 & $38.80 \pm 000$ & $39.00 \pm 39.00$ & $39.00 \pm .000$ & $40.00 \pm .000^{\#}$ & $39.60 \pm 0.55^{\#}$ & $40 \pm 0.00$ \\
\hline \multirow{5}{*}{$\begin{array}{l}\text { Respiratory } \\
\text { rate((min) }\end{array}$} & Before & $40.40 \pm 8.764$ & $35.2 \pm 3.347$ & $33.60 \pm 8.295$ & $44.00 \pm .5 .66$ & $31.60 \pm 8.52$ & $36.96 \pm 8.05$ \\
\hline & After(Rx) & & & & & & \\
\hline & Day1 & $33.60 \pm 7.266$ & $30.40 \pm 4.561$ & $25.60 \pm 4.561$ & $26.00 \pm 4.472^{\#}$ & $24.40 \pm 2.966^{\#}$ & $28 \pm 5.745$ \\
\hline & Day2 & $28.67 \pm 1.16$ & $24.00 \pm 3.266$ & $23.20 \pm 3.347^{\#}$ & $20.80 \pm 3.37^{\#}$ & $20.40 \pm 2.96$ & $26.00 \pm 0.18$ \\
\hline & Day3 & $22.67 \pm 5.03$ & $22.00 \pm 2.309$ & $19.60 \pm 2.966^{\#}$ & $16.80 \pm 1.05^{\#}$ & $17.20 \pm 2.63^{\#}$ & $19.27 \pm 3.47$ \\
\hline
\end{tabular}

Values expressed as (\#) superscript are significantly significant between control groups at $p<0.05$.

Values were expressed by means $\pm S D$ paired t-test before and after treatment by STATA version 14

One way ANOVA followed by Bonferroni post hoc test was used to compare between group 


\subsection{Hematological Results}

The hemoglobin concentration (mean \pm SD) of experimental animals before treatment Group I, II, III, IV, and control group was $14.00 \pm 2.00,15.80 \pm .447$, and $12.80 \pm 1.924,14.40 \pm 1.517,15.40 \pm 1.673$ respectively and after treatment on day one was $13.20 \pm 2.168,14.5 \pm .707,12.10 \pm 2.19,13.80 \pm 1.78$ and $14.80 \pm 2.168$ respectively, $(p<0.05$,). Similarly, all treatment groups were statically significance after treatment on day two and day three $(p<0.05)$, obvious change (Table5).

Animals suffering from experimentally induced acidosis had increased packed cell volume (PCV) initially, however there was a decreased PCV level after treatment regimens were given significantly $(p<0.05)$ between groups apparently treatment Group III (probiotics with rumenotorics) and control group, the mean \pm SD of PCV were statically significance $(p<0.05, p=0.003, p=0.02$ \&0.006) from day one -day three, respectively. Standard treatment was the second level of treatment to improve the disordered of PCV value as well as the third level of treatment was treatment Group II (probiotics with prebiotics). The experimental trial on day two, treatment Group III (probiotics with rumenotorics) blood $\mathrm{pH}$ values was statistically significant $(\mathrm{p}<0.05)$, improved. Therefore, this result was shown that treatment Group III (probiotics with rumenotorics) had a significant effect on the value of PCV for treatment of acidotic sheep and increased blood $\mathrm{pH}$ on day two and day three after treatment, $(\mathrm{p}<0.05)$ whereas the blood $\mathrm{pH}$ was significant $(p<0.05)$ in treatment Group IV at day one up to three .

Table5: Effect of various treatment regimens on hematological parameters on acidotic sheep (mean \pm SD)

\begin{tabular}{|c|c|c|c|c|c|c|}
\hline Parameter & Time of Rx & Control group & Treatment I & Treatment II & Treatment III & Treatment IV \\
\hline \multirow[t]{5}{*}{ Blood pH } & Before & $6.20 \pm 0.447$ & $6.60 \pm .548$ & $6.20 \pm .447$ & $6.60 \pm .548$ & $6.40 \pm .48$ \\
\hline & \multicolumn{6}{|l|}{ After $\left(R_{X}\right)$} \\
\hline & Day 1 & $6.40 \pm 0.548$ & $6.59 \pm .648$ & $6.60 \pm .548$ & $6.80 \pm .447$ & $7.40 \pm .548^{\#}$ \\
\hline & Day2 & $6.00 \pm 0.00$ & $7.00 \pm .00^{\#}$ & $6.68 \pm .547$ & $7.100 \pm .100^{\#}$ & $7.480 \pm .447^{\#}$ \\
\hline & Day3 & $6.67 \pm .577$ & $7.00 \pm 00$ & $7.00 \pm 00^{\#}$ & $7.50 \pm 00^{\#}$ & $7.57 \pm .577^{\#}$ \\
\hline PCV & Before & $44.00 \pm 4.183$ & $42.00 \pm 5.7$ & $41.80 \pm 3.768$ & $38.00 \pm 6.819$ & $44.20 \pm 2.387$ \\
\hline \multirow[t]{4}{*}{$(\%)$} & \multicolumn{6}{|l|}{ After $\left(R_{X}\right)$} \\
\hline & Day1 & $43.20 \pm 3.70$ & $39.00 \pm 3.742$ & $37.40 \pm 2.88^{\#}$ & $34.60 \pm 5.367^{\#}$ & $42.00 \pm 2.345$ \\
\hline & Day2 & $39.00 \pm 1.00$ & $37.25 \pm 4.272$ & $35.60 \pm 1.881$ & $29.80 \pm 6.261^{\#}$ & $39.80 \pm 1.483^{\#}$ \\
\hline & Day3 & $35.55 \pm 7.12$ & $33.00 \pm 3.559$ & $29.40 \pm 2.99 \#$ & $24.80 \pm 10.134^{\#}$ & $37.80 \pm 1.789 \#$ \\
\hline hemoglobin & Before & $15.40 \pm 1.67$ & $14.00 \pm 2.000$ & $15.80 \pm .447$ & $12.80 \pm 1.92$ & $14.40 \pm 1.517$ \\
\hline \multirow[t]{4}{*}{$(\mathrm{gm} / \mathrm{dl})$} & \multicolumn{6}{|l|}{ After $\left(R_{X}\right)$} \\
\hline & Day1 & $14.80 \pm 2.168$ & $13.20 \pm 2.168$ & $14.5 \pm .707$ & $12.10 \pm 2.19$ & $13.80 \pm 1.78$ \\
\hline & Day2 & $13.00 \pm 1.000$ & $12.00 \pm 2.168$ & $11.40 \pm .548$ & $11.40 \pm 1.817^{\#}$ & $13.20 \pm 1.095$ \\
\hline & Day3 & $12.67 \pm .577$ & $11.50 \pm 1.732$ & $11.10 \pm 0.89^{\#}$ & $11.00 \pm 2.121^{\#}$ & $13.00 \pm 1.000$ \\
\hline
\end{tabular}

Values expressed as (\#) superscript are significantly significant between control groups at $p<0.05$.

Values were expressed by means $\pm S D$ paired t-test before and after treatment by STATA version 14

One way ANOVA followed by Bonferroni post hoc test was used to compare between groups 


\subsection{Qualitative and Quantitative Ruminal Fluid Analysis Results}

Chemical and physical examination of ruminal fluid was examined in the present experimental trials. During the induction phase of ruminal acidosis, the ruminal $\mathrm{pH}$, protozoan count and motility were reduced. The cellulose digestion and glucose fermentation activity were completely stopped in almost all sheep as indicated in their respective tests in a laboratory in day zero or before treatment. The examination of ruminal fluid was watery and acidic smell.

Analysis of ruminal fluid pH was increased significantly $(\mathrm{P}<0.05)$ in acidotic sheep after treatment. From a comparison of each treatment groups with the control group, the combination of probiotics with rumenotorics treatment group(III), the mean \pm SD $4.96 \pm .837,5.92 \pm .54,6.30 \pm .41$ and $6.75 \pm 0.34$ was statically significant $(p=0.024,0.047,0.002)$ respectively from day one - day three. The standard treatment Group IV (sodium bicarbonate) was also statically significant $(\mathrm{p}<0.05)$ improved ruminal $\mathrm{pH}$ from day two - day three where as treatment group II was significant difference at day three compare with control group ,it is more elaborated (Table6).

Sedimentation activity time and methylene blue reduction times were significantly differed $(P<0.05)$ in all groups after employed the treatments for three successive days. From treatment groups, probiotics with rumenotorics were found to be significantly $(P<0.05)$ decreased. The mean value of the methylene blue reduction time ( $\mathrm{min})$ before and after treatment was $9.40 \pm 2.302$ and $4.60 \pm 3.507$ respectively (Table6). Also, sedimentation activity time $(\mathrm{min})$ was $1.60 \pm .894$ and $12.00 \pm 3.082$ significantly increased after treatment $(\mathrm{P}<0.05)$. The analysis of qualitative ruminal fluid after treatment such as protozoan motility and concentration was statically significant $(p<0.05)$.

Table6: Effect of various treatment regimens on of rumen liquor experimental induced acidosis in

Sheep

\begin{tabular}{|c|c|c|c|c|c|c|}
\hline Parameter & Time of $\mathrm{Rx}$ & Control group & Treatment I & Treatment II & Treatment III & Treatment IV \\
\hline \multirow[t]{5}{*}{ Ruminal $(\mathrm{pH})$} & Before & $4.40 \pm .54$ & $4.80 \pm .46188$ & 5.00. \pm 447 & $4.96 \pm .837$ & $4.97 \pm .637$ \\
\hline & \multicolumn{6}{|l|}{ After $\left(R_{X}\right)$} \\
\hline & Day1 & $4.96 \pm .43$ & $5.04 \pm .27$ & $5.18 \pm .31$ & $5.92 \pm .54^{\#}$ & $5.38 \pm .540$ \\
\hline & Day2 & $5.31 \pm .53$ & $5.19 \pm .33$ & $5.380 \pm .23$ & $6.30 \pm .41^{\#}$ & $5.85 \pm .540^{\#}$ \\
\hline & Day3 & $5.4333 \pm .4934$ & $5.50 \pm .216$ & $5.880 \pm .19) \#$ & $6.75 \pm 0.34^{\#}$ & $6.42 \pm .570^{\#}$ \\
\hline protozoan & Before & $0.00 *(0 .-00)$ & $0.00 *(0-00)$ & $0.00 *(0-1.00)$ & $0.00 *(0-00)$ & $0.0 *(0-00)$ \\
\hline \multirow[t]{4}{*}{ Motility test } & \multicolumn{6}{|l|}{ After $\left(R_{X}\right)$} \\
\hline & Day1 & $0.00 *(0-1.00$ & $0.00 *(0-2.00)$ & $1.00 *(0-2.00)$ & $2.0 *(0-2.00)$ & $1.00 *(0-1.00)$ \\
\hline & Day2 & $1.00(1.0-1.00)$ & $1.00 *(0-1.00)$ & $1.00 *(1-2.00)$ & $2.0 *(2-3.00) \#$ & $1.00 *(1-1.00)$ \\
\hline & Day3 & $1.00 *(1-2.00)$ & $1.50^{*}(1.00-3.00)$ & $1.00 *(1-300)^{\#}$ & $3.0 *(2-3.0) \#$ & $2.00 *(2-3.00)) \#$ \\
\hline MBRT & Before & $10.33 \pm 1.528$ & $9.25 \pm 1.708$ & $9.40 \pm 2.966$ & $9.40 \pm 2.302$ & $10.20 \pm 1.643$ \\
\hline$(\min )$ & After $\left(R_{X}\right)$ & $9.67 \pm 1.528$ & $8.25 \pm 1.708$ & $7.60 \pm 1.51$ & $4.60 \pm 3.507^{\#}$ & $6.40 \pm 1.673^{\#}$ \\
\hline SAT & Before & $1.33 \pm .577$ & $1.50 \pm .577$ & $1.40 \pm 548$ & $1.60 \pm .894)$ & $1.20 \pm .447$ \\
\hline (Min) & After $\left(\mathrm{R}_{\mathrm{X}}\right)$ & $4.00 \pm 1.000$ & $3.25 \pm .500$ & $6.60 \pm .219^{\#}$ & $12.00 \pm 3.08^{\#}$ & $4.00 \pm 1.000$ \\
\hline
\end{tabular}

Values expressed as (\#) superscript are significantly significant between control groups at $p<0.05$. 
Values are Mean \pm S.D in Paired t-test, the values of protozoan motility was median ( $\left.Q_{0}-Q 3\right)$ and Kruskal-Wallis equality-ofpopulations rank test.

MBRT=Methylene blue reduction time; SAT = Sedimentation activity time of the ruminal fluid before and after treatment between groups

\section{treatments}

Figure2: The mean ruminal pH between treatment groups for three consecutive days.

$p H_{0}=$ ruminal $p H$ on day zero; $p H 1=$ ruminal $p H$ on day one; $p H 2=$ ruminal $p H$ on day two; $p H 3=$ ruminal $p H$ on day three. The $x$-axis is a list of treatments; treatment I - probiotics; Treatment II- probiotics with prebiotics; Treatment III- probiotics with rumenotorics; Treatment IV-standard treatment (sodium-bicarbonate).

\subsection{Serum Analysis Results}

The treatment regimens were revealed statically significant $(p<0.05)$ between groups to improve the abnormal value of enzymatic and protein disorders. From all the treatment Groups II, III and IV were highly significant $(p<0.05)$ for the improvement of total protein, albumin, and AST. The mean values of total protein $(\mathrm{g} / \mathrm{dl})$, albumen $(\mathrm{g} / \mathrm{dl})$ and AST $(\mathrm{u} / \mathrm{L})$ before treatment (IV, III and II) were $5.5 \pm .24,2.08 \pm .36,254 \pm 59$ then it was converted to, $7 \pm .80,3.3 \pm .4,109 \pm 3$ respectively after treatment (Table7). The mean total protein $(\mathrm{g} / \mathrm{dl})$ and albumen concentration of experimental animals for treatment Group III were statistically significant $(p<0.05), 5.2 \pm .54,2.08 \pm .36$ was before treatment then it was changed into $6.8 \pm .40,2.47 \pm .27$ after treatment respectively.

Table7: Various treatment regimens on serum proteins and liver enzyme profile in acidosis sheep

\begin{tabular}{|lllllll|}
\hline Parameter & & Control group & Treatment & Treatment & Treatment & Treatment \\
& & & I & II & III & IV \\
\hline Total proteins & Before & $5.32 \pm .43$ & $5.70 \pm .46$ & $5.75 \pm .54$ & $5.2 \pm .54$ & $5.5 \pm .24$ \\
\hline$(\mathrm{g} / \mathrm{dl})$ & After $\left(\mathrm{R}_{\mathrm{X}}\right)$ & $5.7 \pm .32$ & $5.9 \pm .35$ & $6.00 \pm .63^{*}$ & $6.8 \pm .40$ & $7 \pm .80$ \\
\hline Albumin & Before & $2.17 \pm .47$ & $1.75 \pm .86^{\#}$ & $1.71 \pm .36^{\#}$ & $2.08 \pm .36^{\star}$ & $2.4 \pm .38^{\# \star}$ \\
\hline$(\mathrm{g} / \mathrm{dl})$ & After $\left(\mathrm{R}_{\mathrm{X}}\right)$ & $2.08 \pm .18$ & $2.52 \pm .32$ & $2.3 \pm .10$ & $2.47 \pm .27^{\#}$ & $3.3 \pm .4^{\star}$ \\
\hline AST & Before & $219 \pm 39$ & $241.6 \pm 44$ & $202.4 \pm .36$ & $181 \pm 91^{*}$ & $254 \pm 59^{\star}$ \\
\hline$(\mathrm{U} / \mathrm{l})$ & After $\left(\mathrm{R}_{\mathrm{X}}\right)$ & $232 \pm 28$ & $176 \pm 61.8$ & $173.4 \pm 67$ & $111 \pm 27$ & $109 \pm 34$ \\
\hline ALP & Before & $285 \pm 86$ & $404.3 \pm 46$ & $366 \pm 12$ & $415 \pm 31$. & $434 \pm 42$ \\
\hline$(\mathrm{U} / \mathrm{l})$ & After $\left(\mathrm{R}_{\mathrm{X}}\right)$ & $222 \pm 52$ & $336 . \pm 78$ & $346.7 \pm 99$ & $121.8 \pm 87$ & $99 \pm 43$ \\
\hline
\end{tabular}

Values in each group are significantly different at $p \leq 0.05$ Values are Mean \pm S.D in Paired $t$-test using and ANOVA-post hoc test between groups and control group. *-indicates significantly different from the control group; \#-indicates significantly different between groups; *\#- indicates significantly different between groups and control group

\section{Discussion}

The present experimental model for the induction of ruminal acidosis used in this study aimed to induce a condition that occurred due to wheat flour intake after $24 \mathrm{hrs}$ fasting. Likewise, [31] showed that, for undernourished sheep ( $24 \mathrm{hrs} \mathrm{fasting),} 50 \mathrm{~g} / \mathrm{kg} \mathrm{body}$ weight of wheat were induced clinical signs of acute ruminal acidosis. Induction was effective in causing ruminal acidosis, observed through the manifestation of classic acidosis clinical signs, such as reduced feed intake and rumination, depression, teeth grinding and diarrhea, after acid induction diet. After induction, considerable disparities in the ruminal and blood pH, as well 
as physical parameters among the treatment and control groups, were observed and continue until treatment applied. Unlikely, $[39,24]$ induced acute acidosis in adult sheep after $24 \mathrm{hr}$ fasting by feeding soaked wheat at $90 \mathrm{~g}$ per $\mathrm{kg}$ body weight.

Heart rate and respiratory rates were increased up to $152 / \mathrm{min}$ and $52 / \mathrm{min}$ before treatment in the entire group respectively. Similarly, a study was reported by [7] in acidotic sheep. Increased heart rate might be due to toxic effects of lactic acid, reduced plasma volume and circulatory failure. Increased respiration might be due to stimulation of the respiratory center by the increased carbon-dioxide concentration of blood and reduced blood pH $[7,10]$. Significant differences were found in the pre and posttreatment values of temperature, heart rate, and respiration rate of the groups. Increased heart rate was observed in lactic acidotic sheep for which similar finding has been reported by [40]. Reduced body temperature, expressed in the present study was in accordance with [41] which may be due to ruminal acidosis that led to dehydration.

The marked reduction in ruminal $\mathrm{pH}$ to $4.82 \pm 0.62$, in the present study revealed that acute acidosis was effectively induced. Similar results were observed in previous studies of the induction of acute acidosis reported by [31]. At this low pH, almost entire rumen protozoal activity ceases and no live protozoal population was observed under low power magnification due to lack of nutrients and optimal $\mathrm{pH}$. Reduced ruminal $\mathrm{pH}$ is may be related to VFA production and lactic acid accumulation after feeding a grain diet [42]. The result of this study coincide with findings reported by [22] in acute ruminal acidosis in small ruminants and conversely, induction of acidosis was reported by [43] in sheep by sucrose at a dose of $18 \mathrm{~g} \mathrm{~kg}-1$ bodyweight.

In this study, sheep suffering from induced lactic acidosis showed reduced protozoal motility, glucose fermentation activity, and cellulose indigestion and protozoa number. There was an increase in SAT, MBRT and gram-positive Bactria. Further, increased sedimentation activity and decreased methylene reduction indicates that reduced microbial activity and suppressed microbial fermentation activity. The mean value of the sedimentation activity time before treatment was $1.41 \pm 0.59$, then it changed to $6.91 \pm 3.99$ after treatments as well as the methylene blue reduction time was $9.68 \pm 2.317$, then after treatment it reduced to 7.05 \pm 2 .34. Therefore, there was improvement both SAT and MBRT after treatment. This may be due to increased anaerobic ruminal microbial activity.

The hematological parameters (blood $\mathrm{pH}$, hemoglobin and PCV) were influenced by the experimental induced acidosis such a way that the average PCV value and hemoglobin concentration $(\mathrm{g} / \mathrm{dl})$ was increased in all groups of animals before treatment. A similar result was also reported by [44]. This is may be the result of haemo-concentration and reduced due to increased osmolarity of rumen contents which withdraws fluid from intravascular compartments [45]. The blood pH of the lactic acidotic sheep was found to be lower than the normal value which is a close agreement with [34]. Decreased the pH could be due to overdistention of rumen which impedes venous blood return to the heart. This condition reduced hepatic perfusion and lower lactic acid utilization which in turn leads to systemic lactic acidosis, reflecting by reduced blood $\mathrm{pH}$.

In the present study, after exhaustive therapeutic treatment, the sheep were treated with four treatment regimen and all the animals were recovered and clinically normal after treatment except one of them died even after treatment Group I (probiotics alone). Treatment Group II (probiotics with prebiotics) was a better therapeutic effect than treatment Group I (probiotics alone). This result is consistent with [46] treatment of simple indigestion due to acidosis. This may relate with prebiotics (Fructo Oligo Saccharide) encourage the growth of the beneficial bacteria in the gastro-intestinal tract of the ruminants (20). Feeding FOS helps in the proliferation of these probiotics bacteria which inhibit the growth of more harmful bacteria. It can be postulated that prebiotics provides a substrate for the growth of probiotics [47].

The mortality rate of each treatment group was compared with the control group. The mortality rate of the control group (untreated) highest 2 from 5 sheep (40\%) whereas the treatment group I treated only probiotics, 1 from 5 sheep (20\%) were died in the second day after treatment. In contrast, previous finding reported that case mortality rate could be up to $90 \%$ in untreated cases, while in treated cases could be up to 30-40\% (Bramley et al., 2012) [48]. Other treatment groups such as group II (probiotics with prebiotics), III (probiotics with rumenotorics) and IV (NaHCO3) were not died after treatment. However, their activity and recovery time was different in the different treatment group. In this study, the treatment group I treated by probiotics (bacterial and yeast probiotics) was not statistically significant effect compared with a control group to treat acidotic sheep whereas the combination of probiotics and rumenotorics were most therapeutically effective of acidotic sheep were recovered in day one which is in agreement with finding reported by [46]. This therapeutic combination had better effect on physiological

Page 12/18 
parameters; particularly heart rate and respiratory rate were ameliorated from day one up to day three. This may be due to the synergistic effect of probiotics and rumenotorics and might have augmented the growth of the probiotics as well as the normal beneficial ruminal microbes/ (cellulolytic bacteria), even better than the prebiotics with probiotics combination. Because of in ruminants some of the prebiotics digested by ruminal bacterial action as such some of them remained unavailable to the probiotics or beneficial ruminal microorganism whereas rumenotorics are metallic elements and thus absolutely indigestible by the ruminal microbes.

In this investigational trial, the combination of bacterial probiotics, yeast probiotics and rumenotorics (treatment group III) was more flourishing to recover the ruminal $\mathrm{pH}$ than benchmark treatment (sodium bicarbonate). Because yeast probiotics jointly with bacterial probiotic have a high buffering outcome in the rumen, by intervening the abrupt of rumen cellulolytic (cellulose processing) microorganisms and enhancements within fiber digest [49]. Previous studies showed that the valuable effects on ruminal $\mathrm{pH}$ were observed for acidosis treatments associated with a bacterial probiotics with yeast probiotics without rumenotorics [50]. On the contrary, previous reports showed that the effects of administering single bacterial or yeast probiotic strain in ruminal acidosis have no intense effect on ruminal pH [51]. Alternatively, the supplement of single strain of bacterial probiotic such as Megasphaera elsdenii strain NCIMB 41125 in ruminants can control and prevent ruminal acidosis during the transition period from forage to grain since the bacterium could able to utilize the ruminal lactic acid and keeps it constant [52].

The presence of yeasts lessened the detrimental effects of a pH drop on digestibility of a $70 \%$ concentrate diet; because there is interaction, for fiber digestibility, between the yeast supplementation and the concentrate level [53]. In contrast, [54] found no effect of only S. cerevisiae culture, containing metabolites of yeast fermentation, on ruminal fermentation. The present result suggests that repeated administration of a multi-strain BP reduced in some extent the risk of acidosis with consecutive treatment in sufficient dose of BP containing yeast probiotics while bacterial probiotics with yeast probiotics together with rumenotorics improve absolutely ruminal $\mathrm{pH}$. This may due to increasing the activity of lactate consuming bacteria and rumenotorics act as cofactors required for vitamin B12 synthesis as well as a substrate for growth of rumen microbe's restoration of deranged rumen function and subsequent revival of appetite [55]. In the current study, the standard treatment Group IV (sodium bicarbonate) was also statically significant $(\mathrm{p}<0.05)$ improved ruminal $\mathrm{pH}, 4.97 \pm .637$ before treatment, then it changes into $5.85 \pm .540,6.42$ \pm .570 from day two and day three, respectively, pos treatments.

All of the treatments were able to correct the acidotic condition of blood parameters after their administration which was evident from the increased blood $\mathrm{pH}$, reduced PCV and hemoglobin concentration. In contrast, the findings disagree with of [56] findings, who demonstrated that use probiotics as supplementation results statistically significant increase in the hemoglobin concentration and haematocrit value. Other study also reported that probiotics did not affect the blood constituents comprising, hemoglobin concentrations [57]. This experimental study provides probiotics with rumenotorics and probiotics with prebiotics was most successful to correct the concentration of hemoglobin. Because probiotics yeast and bacteria combined with prebiotics or rumenotorics have different mechanisms of action, a synergetic effect and higher viability might be expected from mixing both types of probiotics [58]. Meanwhile, PCV and blood pH were improved by treatment group III (probiotics with rumenotorics) as well as treatment group IV (sodium bicarbonate). Cumulatively, the blood pH was corrected earlier by sodium bicarbonate than probiotics with rumenotorics. The change blood $\mathrm{pH}$ was higher on day one after the treatment by sodium bicarbonates. This possibly will be due to sodium bicarbonate can multiply the the concentration of a solution, water utilization, and increments the dilution rate of the Volatile Fatty Acid within the rumen and the path rate of the liquor phase [59]. The strong ion difference theory recommends that any orally managed Sodium compound of which the corresponding anion of the salt is either metabolized or not retained might be powerfully promote the blood pH as sodium bicarbonate acts in two ways: because a foundation of sodium to convene the prerequisites and help offer a definite equilibrium in positively charge ion to negatively charge ion ratio [60].

\section{Conclusion And Recommendations}

In conclusion, the adopted model was successfully induced acute rumen acidosis in sheep as indicated by clinical signs, significant changes in rumen fluid and hematologic parameters. Repeated therapeutic combination of probiotics was provided the optimal solution for microbial composition and functional ruminal disorder as well as correction of hematological disorders due to experimental induced rumen acidosis. Therefore, results from the present experiment indicates that probiotics with

Page $13 / 18$ 
rumenotorics and standard treatment (sodium bicarbonate) were Comparatively provided better therapeutic modality for treating experimental induced rumen acidosis in sheep. Moreover, probiotics along with rumenotorics treatment provides superior effectiveness over other treatments groups. So, the present work could provide a guide to veterinary professionals for amelioration of rumen acidosis and can used by clinician for early recovery those animals affected by ruminal acidosis. By considering the above conclusion the following recommendations were forwarded;

- To treat acidosis in ruminant animals bacterial probiotics and yeas probiotics along with rumenotorics should be treated

- Administration of probiotics should be combined with their substrates

- Stringent quality assurance measures are recommended in this regard using microbes as probiotics only with the proven absence of transferable antibiotic resistance genes.

- During treatment of acidosis with common standard antacids treatment, other supplements should be given.

- Treatment of acidosis by probiotics should be recommended for longer therapeutic periods.

\section{Declarations}

\section{ACKNOWLEDGMENTS}

First, I would like to praise the almighty God with his mother St. Mary for his endless mercy. I am grateful for the financial support obtained from the project and it is also my pleasure to acknowledge Dr. Ashenafi Assefa, my co-advisor and investigator of the project and Co-investigator, Dr Abid Ali. I am highly indebted to my principal advisor, Dr.Wudu Temesgen for his judicious supervision, keen interest, constructive criticism and expert guidance inculcated in me a sense of activism, which turned my aspiration into a concrete reality with the completion of this thesis. This study was done under the Thematic Research Project, "Study on the therapeutic efficacy of different treatment regimens of major ruminal disorders in sheep

No appropriate word could be traced in the presently available lexicon to express my indebtedness and gratitude to my wife Atsede Solomon for her mental support and wholehearted cooperation during the process of thesis work. I am thankful to department staff, especially Miss. Fascia Moges for her invaluable help and kind co-operation throughout the course of study. At this inexplicable moment, words are not in the lexicon to express my sincere sense of gratitude, but with full honor and ecstasy of delight, I express my heartfelt, sincere thanks to Mr.Birhanu Anagaw and Abibo Wondie (clinical pathology Laboratory Technician and Pharmacist) for his constant support from the beginning, valuable suggestions and useful discussions during my entire work. Finally, I am thankful to farm workers especially animal attendants, Miss. Desta Knife. Above all, I thank the almighty for giving me patience and strength to overcome the difficulties, which crossed my way in accomplishment at this endeavor

\section{Authors' contributions}

Melkie Dagnaw and Wudu temesgen were prepared the writing of the first draft of the proposal. Ashenafi Assefa were and Atsede Solomon were performed with regarding to drug dose preparation, follow up the experimental animals before and after treatment. All the authors were participated in manscript writing from introduction up to the discusion.

Wudu temesgen and melkie dagnaw was particularly contribute for the methodology of the experiment and statistical analysis.

\section{Competing interests}

The authors declare that they have no competing interest

\section{Author details}

All the authors are staff of University of Gondar at veterinary college and animal sciences.

\section{References}


1. Asche, F., Bellemare, M. F., Roheim, C., Smith, M. D. \& Tveteras, S. (2015). Fair enough? Food security and the international trade of seafood. World Development,67: 151-160.

2. Mengesha, M. \& Tsega, W. (2012). Indigenous sheep production in Ethiopia: A Review. Iranian Journal of Applied Animal Science,2: 311-318.

3. Gizaw, S., Komen, H., Hanotte, O. \& Van Arendonk, J. A. (2008). Indigenous sheep resources of Ethiopia: types, production systems and farmers preferences. Animal Genetic Resources/Resources génétiques animales/Recursos genéticos animales,43: 25-39

4. Shad, F., Tufanil, N., Ganie, A. \& Ahmed, H. (2011). Flushing in ewes for higher fecundity and fertility. Livestock international,15: 10-1.

5. Hassen, A., Ebro, A., Kurtu, M. \& Treydte, A. (2010). Livestock feed resources utilization and management as influenced by altitude in the Central Highlands of Ethiopia. Livestock Research for Rural Development, 22.

6. Gizaw, S., Komen, H., Hanotte, O. \& Van Arendonk, J. A. (2010). Indigenous sheep resources of Ethiopia: types, production systems and farmers preferences. Animal Genetic Resources/Resources génétiques animales/Recursos genéticos animales,43: 25-39

7. Radostits, O., Gay, C., Hinchclitt, K. \& Constable, P. (2010). Veterinary Medicine, a Text Book of the Disease of Cattle, Horses, Sheep, Goats, and Pigs. New York: Elsevier.

8. SARGISON, N. \& SCOTT, P. (2010). The implementation and value of diagnostic procedures in sheep health management. Small Ruminant Research,92: 2-9.

9. RAGFAR. (2007): Ruminal Acidosis prevention and treatment. Journal of animaL Science,4(10): 20-56

10. Allen, H. K., Levine, U. Y., Looft, T., Bandrick, M. \& Casey, T. A. (2013). Treatment, promotion, commotion: antibiotic alternatives in food-producing animals. Trends in microbiology,21:114-119.

11. Dhanapalan, P. and R. (2001). Anatomy of the Ruminant Stomach and its Application in Ruminant Medicine. Training Manual on Ruminant Medicine,5: 150-220

12. Singh, D. (2017). Clinical study on bovine ruminal acidosis with reference to its impact on liver and kidney functions and therapeutic management. Sher-e-kashmir university of agricultural sciences and technology of jammu.

13. Roberfroid, M., Gibson, G. R., Hoyles, L., Mccartney, A. L., Rastall, R., Rowland, I., Wolvers, D., Watzl, B., Szajewska, H. \& Stahl, B. (2010). Prebiotic effects: metabolic and health benefits. British Journal of Nutrition,104:S1-S63.

14. Aschenbach, J, Penner, G., Stumpff, F. \& Gäbel, G. (2011). Ruminant nutrition symposium: Role of fermentation acid absorption in the regulation of ruminal pH. Journal of Animal Science,89: 1092-1107.

15. Kenney, N., Vanzant, E., Harmon, D. \& Mcleod, K. (2015). Direct-fed microbials containing lactate-producing bacteria influence ruminal fermentation but not lactate utilization in steers fed a high-concentrate diet. Journal of animal science,93: 23362348.

16. Seo, J. K., Kim, S.-W., Kim, M. H., Upadhaya, S. D. \& Kam, D. K. (2010). Jong K. Ha Directfed Microbials for Ruminant Animals Asian-Aust. J. Anim. Sci,23:1657-1667

17. Kays, S. J. \& Nottingham, S. F. (2007). Biology and chemistry of Jerusalem artichoke: Helianthus tuberosus L, CRC press.

18. Callaway, T., Edrington, T., Anderson, R., Harvey, R., Genovese, K., Kennedy, C., Venn, D. \& Nisbet, D. (2008). Probiotics, prebiotics and competitive exclusion for prophylaxis against bacterial disease. Animal Health Research Reviews,9:217-225.

19. Adesogan, A. T. (2009). Using dietary additives to manipulate rumen fermentation and improve nutrient utilization and animal performance. Proceedings: 20th florida ruminant nutrition symposium. Gainesville,13-37.

20. Simon, O., Jadamus, A. \& Vahjen, W. (2001). Probiotic feed additives-effectiveness and expected modes of action. Journal of Animal and Feed Sciences, 10:51-68.

21. Shah, O.S., Hussain, T., Amin, U., Rouf, A., Dar, Z.A., Nabi, S.U. and Shaheen, M., (2017). Efficacy of different therapeutic regimens for simple indigestion in sheep.

22. Tufani, N., Makhdoomi, D. \& Hafiz, A. (2013). Rumen acidosis in small ruminants and its therapeutic management. Iranian Journal of Applied Animal Science, 3, 19-24.

Page 15/18 
23. Walker, B. (2006). Grain poisoning of cattle and sheep, 330(3) 87-120

24. Minuti, A., Ahmed, S., Trevisi, E., Piccioli-Cappelli, F., Bertoni, G., Jahan, N. and Bani, P., (2014). Experimental acute rumen acidosis in sheep: consequences on clinical, rumen, and gastrointestinal permeability conditions and blood chemistry. Journal of Animal Science, 92(9), pp.3966-3977.

25. Zebeli, Q., Aschenbach, J., Tafaj, M., Boguhn, J., Ametaj, B. \& Drochner, W. (2012). Invited review: Role of physically effective fiber and estimation of dietary fiber adequacy in high-producing dairy cattle. Journal of Dairy Science,95:1041-1056.

26. Ametaj, B.N., Koenig, K.M., Dunn, S.M., Yang, W.Z., Zebeli, Q. and Beauchemin, K.A., (2009). Backgrounding and finishing diets are associated with inflammatory responses in feedlot steers. Journal of animal science, 87(4), pp.1314-1320.

27. Der Bedrosian, M. (2009). The effect of sodium bicarbonate or live yeast culture (Saccharomyces cerevisiae) on the metabolism and production of Lactating dairy cows. University of Delaware.

28. Rigobelo, E. C. \& De Ávila, F. A. (2012). Protective effect of probiotics strains in ruminants. Probiotic in Animals. IntechOpen

29. Heng, N.C., Wescombe, P.A., Burton, J.P., Jack, R.W. and Tagg, J.R., (2007). The diversity of bacteriocins in Gram-positive bacteria. In bacteriocins(pp. 45-92). Springer, Berlin, Heidelberg.

30. Campbell, A. A. (2010). Optimizing the adaptation rate of feedlot steers dosed with Megasphaera elsdenii NCIMB 41125 and fed high starch diets. University of Pretoria.

31. Minuti, A., Ahmed, S., Trevisi, E., Piccioli-Cappelli, F., Bertoni, G., Jahan, N. \& Bani, P. (2014). Experimental acute rumen acidosis in sheep: Consequences on clinical, rumen, and gastrointestinal permeability conditions and blood chemistry. Journal of animal science,92: 3966-3977.

32. Markowiak, P. and Śliżewska, K., (2017). Effects of probiotics, prebiotics, and synbiotics on animal health. Nutrients, 9(9), p.1021.

33. Dalcin, V. C., Fischer, V., Daltro, D. D. S., Alfonzo, E. P. M., Stumpf, M. T., Kolling, G. J., Silva, M. V. G. B. D. \& Mcmanus, C. (2016). Physiological parameters for thermal stress in dairy cattle. Revista Brasileira de Zootecnia,45: 458-465.

34. Ullah, H., Khan, J., Khan, M., Sadique, U., Shah, M., Idrees, M. \& Shah, Z. (2013). Clinico-therapeutical trials of lactic acidosis in small ruminants. JAPS, Journal of Animal and Plant Sciences,23: 80-83.

35. Marzouk, M.S., Moustafa, M.M. and Mohamed, N.M., (2008). Evaluation of immunomodulatory effects of some probiotics on cultured Oreochromis niloticus. In 8th International symposium on tilapia in aquaculture(Vol. 1043).

36. Khan, J. A., Khan, M. S., Sadique, U., Shah, M., Idrees, M., and Shah, Z. (2013):Clinico-Therapeutical Trials of Lactic Acidosis in Small Ruminants. The Journal of Animal and Plant Sciences,23(1): 80-83

37. Gentile, A., Sconza, S., Lorenz, I., Otranto, G., Rademacher, G., Famigli-Bergamini, P. \& Klee, W. (2004). D-lactic acidosis in calves as a consequence of experimentally induced ruminal acidosis. Journal of Veterinary Medicine Series A, 51: 64-70.

38. Mohamed, A. E. A. (2014): Studies on Ruminal Disorders in Sheep. Assiut Vet. Med, Tropical animal health and production,41: 1393.

39. Lettat, A., Nozière, P., Silberberg, M., Morgavi, D. P., Berger, C. \& Martin, C. (2012). Rumen microbial and fermentation characteristics are affected differently by bacterial probiotic supplementation during induced lactic and subacute acidosis in sheep. BMC microbiology, 12: 142.

40. Hajikolaei, M. H., Nouri, M., Afshar, F. S. \& Dehkordi, A. J. (2006). Effects of experimentally induced ruminal lactic acidosis on blood pH, bicarbonate and pCO2 in the sheep. Pak. J. Biol. Sci,9:2003-2005.

41. Khafipour, E., Krause, D.O. and Plaizier, J.C., (2009). A grain-based subacute ruminal acidosis challenge causes translocation of lipopolysaccharide and triggers inflammation. Journal of dairy science, 92(3), pp.1060-1070.

42. Aschenbach, J, Penner, G., Stumpff, F. \& Gäbel, G. (2011). Ruminant nutrition symposium: Role of fermentation acid absorption in the regulation of ruminal pH. Journal of Animal Science,89: 1092-1107.

43. Jafari-Dehkordi, A., Haji-Hajikolaei, M.R. and Karimi-Dehkordi, Z., (2011), September. ECG changes in acute experimental ruminal lactic acidosis in sheep. In Veterinary Research Forum(Vol. 2, No. 3, pp. 203-208). Faculty of Veterinary Medicine, Urmia University

44. Mohan, G.C., Naik, B.R. and Kumar, A.C., (2015). Therapeutic efficacy of poly-herbal formulations andn heterologous cud transplantation with probiotics in ameliorating simple indigestion in buffaloes. Int J PharmBio Sci, 6, pp.3846 
45. Nithin, B. (2017). Evaluation of Essential Oils as an Adjunct Therapy in the Treatment of Lactoacidosis in Goats (Capra hircus). College of Veterinary \& Animal Sciences, Parbhani, MAFSU, Nagpur.

46. Shah, O., Hussain, T., Amin, U., Rouf, A., Dar, Z., Nabi, S. \& Shaheen, M. (2017). Efficacy of different therapeutic regimens for simple indigestion in sheep

47. 47. Losada, M.A. and Olleros, T., (2002). Towards a healthier diet for the colon: the influence of fructooligosaccharides and lactobacilli on intestinal health. Nutrition research, 22(1-2), pp.71-84.

48. Bramley, E., Lean, I., Fulkerson, W. \& Costa, N. (2012). Feeding management and feeds on dairy farms in New South Wales and Victoria. Animal Production Science,52:20-29.

49. Nocek, J. E. and Kautz, W. P. (2006). Direct-fed microbial supplementation on ruminal digestion, health, and performance of pre- and postpartum dairy cattle. J. Dairy Sci. 89: 260-26

50. Chiquette, J., Allison, M. \& Rasmussen, M. (2012). Use of Prevotella bryantii 25A and a commercial probiotic during subacute acidosis challenge in midlactation dairy cows. Journal of dairy science, 95 : 5985-5995

51. Bach A, Iglesias D, Devant M. (2007. Daily rumen pH pattern of loosehoused dairy cattle as affected by feeding pattern and live yeast supplementation. Anim Feed Sci Tech 136:146-153

52. Vyas D, Uwsvizeye A, Mohammed R, Yang WZ, Walker ND, et al. (2014a). The effects of active dried, killed dried yeast on subacute ruminal acidosis, ruminal fermentation and nutrient digestibility in beef heifers. J Anim Sci 92: 724-732

53. Habeeb, A.A.M., (2017). Current View of the Significance of Yeast for Ruminants a Review 1-Role of Yeast and Modes of Action. American Journal of Information Science and Technology, 1(1), pp.8-14.

54. Henning P, Horn C, Stein D, Meissner H, Hagg F. (2010). The potential of Megasphaera elsdenii isolates to control ruminal acidosis. AnimFeed Sci Tech 157: 13-19

55. Carro, M.D.,Lebzien, P.,and Rohr, K. (2014). Influence of yeast cultureon the in vitro fermentation (Rusitec) of diets containing variable portions of concentrate. Anim. Feed Sci. Technol. 37: 219-229

56. Hristov, A.N., Varga, G., Cassidy, T., Long, M., Heyler, K., Karnati, S.A., Corl, B., Hovde, C.J. and Yoon, I., 2010. Effect of Saccharomyces cerevisiae fermentation product on ruminal fermentation and nutrient utilization in dairy cows. Journal of Dairy Science, 93(2), pp.682-692.

57. Rowley, C.A. and Kendall, M.M., (2019). To B12 or not to B12: Five questions on the role of cobalamin in host-microbial interactions. PLoS pathogens, 15(1), p.e1007479

58. Cetin,N,Gu,C,Lu,B.K.,Cetin,E.,(2005).the effects of probiotics and mannanosachride on some heaematological and immunological parameters.JVMS. A-physiology pathology veterinary medicine 52:263-267

59. Dimcho.D.,Svetlana,B.,Tsvetomira.S.,Tatiana,.V. (2005). Effect of feeding Lactina probiotic onperformance, some blood parameters and caecalmicroflora of mule ducklings. Trakia Journal of Sciences 3: 22-2

60. Rima, H., Steve, L. and Ismail, F., (2012). Antimicrobial and probiotic properties of yeasts: from fundamental to novel applications. Frontiers in microbiology, 3, p.421.

61. Gastaldello A, Pires A, Susin I, Mendes C, Quiroz M, et al. (2013). Limestone with different particle size and sodium bicarbonate to feedlot lambs fed high grain diets with or without monensin. Small Ruminant Res 114, 80-85.

62. Lean, I. J., Golder, H. M. \& Hall, M. B. (2014). Feeding, evaluating, and controlling rumen function. Veterinary Clinics: Food Animal Practice,30: 539-575.

\section{Figures}



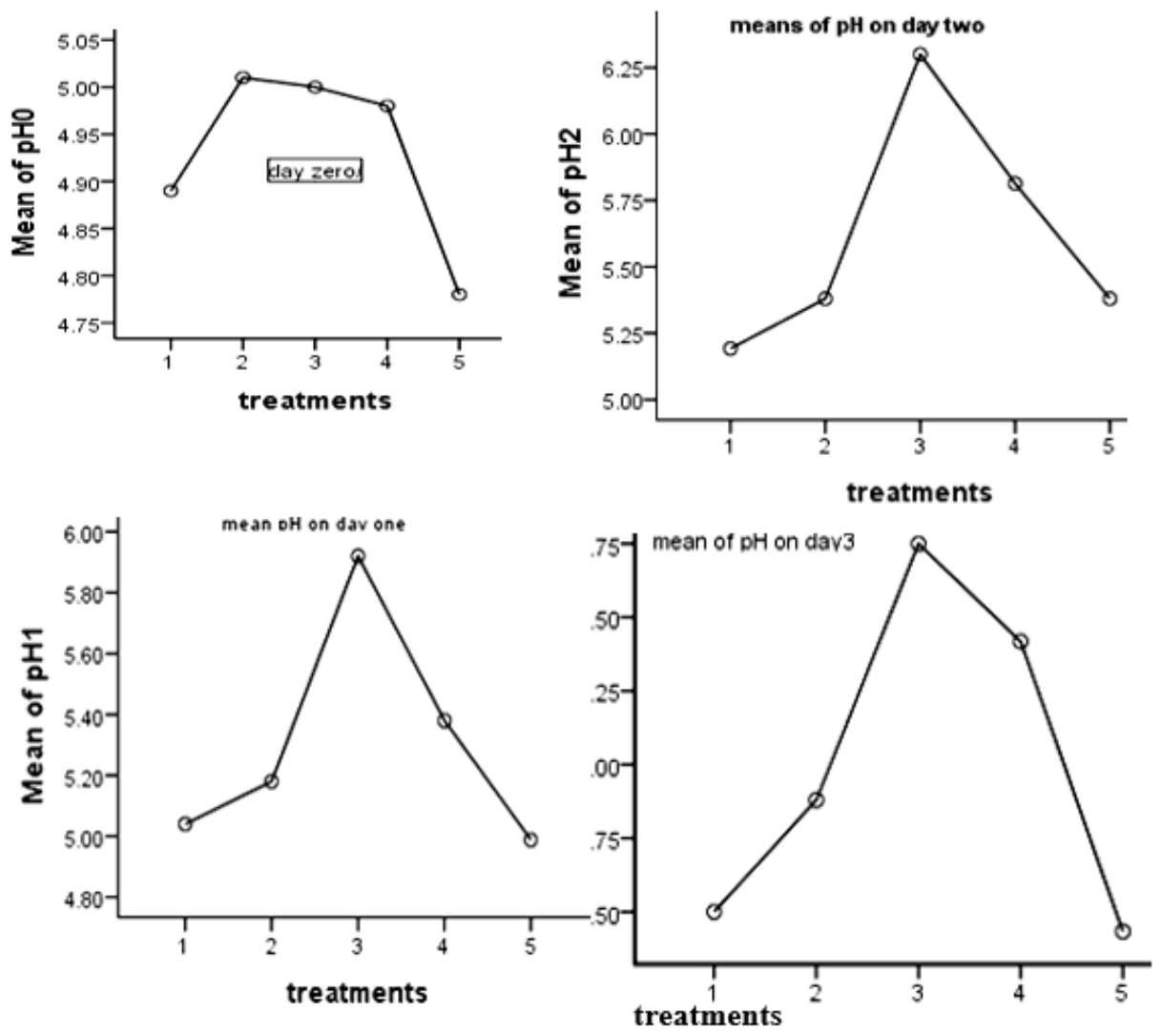

\section{Figure 1}

The mean ruminal $\mathrm{pH}$ between treatment groups for three consecutive days. $\mathrm{pH} 0=$ ruminal $\mathrm{pH}$ on day zero; $\mathrm{pH} 1=$ ruminal $\mathrm{pH}$ on day one; $\mathrm{pH} 2=$ ruminal $\mathrm{pH}$ on day two; $\mathrm{pH} 3=$ ruminal $\mathrm{pH}$ on day three. The $\mathrm{x}$-axis is a list of treatments; treatment I -probiotics; Treatment II- probiotics with prebiotics; Treatment III- probiotics with rumenotorics; Treatment IV-standard treatment (sodiumbicarbonate). 